\title{
Analizar la urbanización latinoamericana \\ a partir de la heterogeneidad de modalidades de producción y consumo
}

\author{
Pedro Tomás Pírez*
}

Resumen Este artículo propone un esquema para analizar la urbanización capitalista en general. Partimos de entender la urbanización como un proceso por medio del cual la población ocupa un espacio que ha sido transformado para soportar su asentamiento aglomerado. Espacio habilitado, o adecuado que resulta de procesos productivos particulares cuyos productos son los componentes de la urbanización. Es por ello por lo que esta última depende del predominio, en cada lugar y momento, de ciertas modalidades particulares de producción. El artículo propone analizar la urbanización en el capitalismo y en el capitalismo dependiente latinoamericano y su fuerte heterogeneidad de modalidades de producción - consumo que se combinan y articulan.

Palabras-clave: urbanización latinoamericana, modalidades de producción-consumo.

\section{Analisar a urbanização latino-americana a partir da heterogeneidade dos modos de produção e consumo}

Resumo Este artigo propõe um esquema para analisar a urbanização capitalista em geral. Partimos da compreensão da urbanização como um processo através do qual a população ocupa um espaço que foi transformado para sustentar seu assentamento aglomerado. Espaço qualificado, ou adequado, que resulta de processos produtivos particulares cujos produtos são componentes da urbanização. É por essa razão que os últimos dependem da predominância, em cada lugar e momento, de certas modalidades particulares de produção. O artigo propõe analisar a urbanização no capitalismo e no capitalismo latino-americano dependente e sua forte heterogeneidade de modalidades de produção-consumo, que são combinadas e articuladas.

Palavras-chave: urbanização latino-americana, modalidades de produção-consumo.

\section{Analyze Latin American urbanization- from the heterogeneity of the modes of production and consumption}

\begin{abstract}
This article proposes a scheme to analyze capitalist urbanization in general. We start from understanding urbanization as a process through which the population occupies a space that has been transformed to support its agglomerated settlement. Qualified or adequate space that results from productive processes whose products are the components of urbanization. It is for this reason that the latter depends on the predominance, in each place and time, of certain modalities of production. The article proposes to analyse urbanization in capitalism and in dependent Latin American capitalism and its strong heterogeneity of production - consumption modalities that are combined and articulated.
\end{abstract}

Keywords: Latin American urbanization, modalities of production-consumption. 
1 La proposición anterior es una simplificación, ya que no toma en cuenta la compleja relación entre valor de las mercancías y precio de producción, ni la relación entre la ganancia del capital individual y la plusvalía como masa social que es apropiada por el capital en su conjunto.

* Pedro Tomás Pírez es abogado, investigador del Consejo Nacional de Investigaciones Científicas y Técnicas (CONICET), Universidad de Buenos Aires, Argentina. ORCID <https://orcid.org/00000003-2833-7767>.
Este artículo propone un esquema analítico para estudiar los procesos de urbanización en las sociedades dependientes de América Latina. Se sustenta en la consideración general de la urbanización en el capitalismo y, de manera particular, en sus condiciones particulares en las sociedades latinoamericanas, identificando sus rasgos propios diferenciables.

La urbanización es considerada un proceso por el cual la población ocupa un espacio que ha sido transformado para soportar el asentamiento aglomerado de la población. En primera instancia, es entendida como habilitación, o adecuación, de una porción de la superficie de la tierra como suelo urbano: segmento espacial que puede sostener las construcciones que hacen posible el asentamiento social aglomerado. El suelo urbano es, entonces, una porción urbanizada de la superficie de la Tierra (lotes, viviendas, infraestructuras y equipamientos, locales para actividades, etcétera) que puede soportar la reproducción de la vida social aglomerada, al sostener al conjunto de las relaciones que estructuran y/o desestructuran a cada sociedad en particular: "acumulación del capital (producción, circulación y cambio), reproducción de la población (fuerza de trabajo y no trabajo), reproducción de lo jurídico-político (política y Estado) y de lo ideológico" (Pradilla, 2013:186).

Estudiar la urbanización en América Latina es identificar cómo se produce-consume ese conjunto de bienes en sociedades capitalistas dependientes, en los diferentes momentos en los que esos procesos se desenvuelven.

\section{La urbanización capitalista}

En una economía capitalista, tendencialmente, todo bien producido es una mercancía, esto es un "objeto externo, una cosa apta para satisfacer necesidades humanas", reales o de fantasía: un "bien de uso", que al mismo tiempo constituye "el soporte material del valor de cambio" que resulta de la aplicación de una determinada proporción de trabajo humano abstracto, una cierta cantidad de "tiempo de trabajo socialmente necesario" (Marx, 1973:3-6). Cuando un bien de uso, que es el "soporte" del valor creado por el trabajo, se introduce en el intercambio (como "bien de cambio"), es posible realizar la plusvalía generada en su producción, alimentado la acumulación de capital ${ }^{1}$. En esas relaciones, el trabajo es "tratado" como mercancía en una construcción histórica que diferencia a quienes poseen (propiedad) los medios de producción de quienes solamente poseen su fuerza de trabajo. Esta se incorpora como valor de uso (capacidad de producción de valores de uso) y valor de cambio ("valor de los medios de vida necesarios para asegurar la subsistencia de su poseedor" -Marx, 1973:124). En esa relación, la fuerza de trabajo produce bienes de uso cuyo valor de cambio supera al propio, generando un excedente que es apropiado como ganancia. En la medida que el salario se fija por debajo de su valor de cambio, es imposible para los asalariados adquirir mercantilmente "todas las mercancías necesarias a la reproducción 
2 Veremos en el capitalismo dependiente de América Latina, junto a esas tres fuentes de ingresos, una presencia importante de formas mercantiles simples ("informales"). de la fuerza de trabajo" (Topalov, 1979:60 y 65). La consolidación del capitalismo industrial implicó, también, la mercantilización del suelo, para integrarlo, junto con la fuerza de trabajo, en las condiciones particulares de producción: suelo donde asentar el taller, fuerza de trabajo, maquinarias, etc., accesibles mercantilmente. Garantizando así a los capitales individuales la disponibilidad de esas condiciones necesarias para sus procesos de acumulación.

Ese proceso de mercantilización puede representarse en dos dimensiones: la producción de bienes de uso cuya incorporación al mercado permite captar una suma monetaria que cubre costos e incluye la ganancia del capital; y el acceso a esos bienes que depende de la posibilidad de contar con los recursos monetarios suficientes para adquirirlos en el mercado: el consumo mercantilizado (Topalov, 1979).

La consolidación de las relaciones capitalistas, y la creciente mercantilización que implicó, supuso el debilitamiento, y en gran medida la desaparición, de derechos y producciones (tradicionales, precapitalistas) que permitían acceder de manera no capitalista (no mercantil) a bienes necesarios para la reproducción de la población. Esa reproducción, por lo tanto, quedó subordinada a la capacidad de pagar las cantidades monetarias que se establecen en el intercambio (demanda solvente).

La tendencia a la mercantilización universal incluyó a la urbanización. En tanto mercancías, los componentes de la urbanización (suelo, vivienda, infraestructuras, etc.) resultan organizados por una lógica estructural de obtención de ganancia: se producen para satisfacer la necesidad de individuos o familias de asentarse de manera urbana (bien de uso) siempre y cuando su introducción en el mercado, como bienes de cambio, permita obtener la cantidad monetaria suficiente para realizar el circuito de la acumulación. Por lo mismo, la población (fuerza de trabajo o no) depende de su capacidad monetaria (solvencia) para acceder a la urbanización, así como a los demás medios necesarios para su reproducción.

Los ingresos que sostienen la capacidad de consumo (solvencia) se originan, predominantemente, en tres fuentes de recursos monetarios: ganancia, renta o salario ${ }^{2}$. La población no propietaria (de medios de producción o de inmuebles) debe someterse, por un salario, al mercado de fuerza de trabajo. Como consecuencia, ciertas familias tienen serias dificultades para contar con los recursos monetarios suficientes para adquirir la totalidad de los bienes que necesitan para su reproducción. Dado, además, que los componentes de la urbanización se caracterizan por su alto costo (Jaramillo 1981:21), resultan especialmente difíciles de adquirir para gran parte de la población. Es evidente, entonces, que la solvencia es el resultado, por un lado, de las condiciones de acceso a los ingresos sociales y su distribución y, por el otro, de las condiciones de los mercados de bienes urbanos, en particular del suelo.

En la vivienda, como en la urbanización en su conjunto, esa contradicción asume una situación especial. Como valor de cambio, esos bienes son un componente de la valorización de los capitales que los producen y hacen circular (inmobiliarios, de la construcción, comerciales y financieros) y como valor de uso son un componente de la reproducción de la fuerza de trabajo en su conjunto. La valorización de los capitales de ese sector se contradice con el hecho de que el valor de cambio del producto es inaccesible a gran parte de la población; mientras que la reproducción de la fuerza de 


\begin{abstract}
3 Esta práctica es estructuralmente limitada ya que los productores no pueden imponer sus necesidades como finalidad de la producción capitalista. Esa finalidad es la ganancia y la acumulación de capital. La manutención de la fuerza de trabajo es un medio para ello, con la salvedad de los límites impuestos por las luchas populares y la necesidad de mercados de consumo (Topalov, 1979:56).
\end{abstract}

trabajo en general se contradice con el hecho de que los capitales del sector inmobiliario no producen un valor de uso indispensable (accesible) (Topalov, 1979:89).

Frente a esas contradicciones se configuran históricamente tres tipos de respuestas: "prácticas sociales de consumo" que enfrentan las limitaciones de manera inmediata y parcial, en general bajo la forma de autoabastecimiento individual o colectivo; reivindicaciones salariales para acceder a consumos mercantilizados necesarios para la reproducción ${ }^{3}$; y reivindicaciones para el reconocimiento social directo de los bienes excluidos del valor de intercambio de la fuerza de trabajo (Topalov, 1979:60-61).

La mirada convencional sobre el desarrollo del capitalismo supuso la desaparición de las formas no capitalistas y la configuración de un "sistema público de mantenimiento de la fuerza de trabajo" (Topalov, 1979:61). En términos generales las contradicciones fueron enfrentadas con acciones específicas a cargo del Estado como garante de la reproducción de las relaciones capitalistas (Offe 1990), configurando, en una larga y sinuosa historia desde mediados del siglo XIX, al Estado de Bienestar, cuyo predominio caracterizó los treinta años posteriores a la segunda posguerra en las sociedades capitalistas avanzadas (Esping-Andersen 1993, Offe 1990, Topalov 1979).

Lo anterior se concretó en dos formas. Una forma monetaria, consistente en ayudas en dinero que implican financiamiento público del consumo popular, y que si bien liberan (relativamente al menos) a los consumidores de su dependencia de los ingresos salariales, consolidan la producción mercantilizada de los bienes de que se trate. En estos casos, son recursos monetarios distribuidos por el Estado "de manera independiente del valor de cambio de la fuerza de trabajo de los beneficiarios" (Topalov, 1979:80) que facilitan ciertos consumos. Una forma no monetaria, sobre la base de "una producción, o al menos una gestión no capitalista de medios de consumo proporcionados a la población de modo no mercantilizado." Esto puede suponer la destrucción de la forma mercantilizada de circulación, con el abastecimiento gratuito o a un precio sin relación con el costo, o relativo a los ingresos de los beneficiarios; o bien el abastecimiento a un precio de costo para el Estado, sin incluir la ganancia capitalista (Topalov, 1979:78).

Como sugerimos antes, esas acciones estatales no son una mera respuesta "estructural". Se dan dentro de un conjunto de condiciones: la relevancia del excedente de la mano de obra en cada sociedad y en diferentes momentos; la existencia de prácticas sociales no mercantiles de reproducción de la fuerza de trabajo; las luchas sociales: relativas a la reproducción de la fuerza de trabajo, entre los trabajadores y el capital, como entre diferentes fracciones (inmobiliario y resto) del capital; y la "capacidad" (económica, y sobre todo política) del Estado para desarrollar actividades y destinar recursos fiscales.

Por otra parte, esas participaciones del Estado tienen en una significación diversa. Permiten que cierta producción (circulación y consumo) deje de desenvolverse exclusivamente en sentido mercantil, dada la aplicación de una capacidad (poder) político-administrativa de regulación (orientar desde fuera del mercado) estatal, junto con la posibilidad, contradictoria, de que esa capacidad controle las relaciones privadas de intercambio (Offe, 1990:56). Como consecuencia la reproducción de individuos y familias deja de depender únicamente del circuito mercantil. 
4 Puede considerarse desmercantilización del consumo cuando el monto monetario que se intercambia no está determinado por la cobertura de costos y ganancia, sino por una relación con el salario de quien lo consume.

5 Esto puede depender de la existencia de alguna limitación legal sobre esa posterior mercantilización. Limitaciones que pueden ser superadas en lo que suele llamarse procesos informales.

6 Versiones anteriores de esta sección fueron presentadas en Pírez 2016
En el Estado de Bienestar esa participación se desenvolvió con tres tipos de procesos junto con la producción-consumo mercantil de la urbanización: producción no mercantil, destinada a su consumo sin pasar por el mercado, como en la educación pública o la vivienda estatal; desmercantilización total o parcial de procesos productivos originalmente mercantiles; y el incremento de las capacidades de solvencia, o desmercantilización del consumo ${ }^{4}$.

La combinación de procesos de producción y de consumos mercantiles, no mercantiles o desmercantilizados limita el predominio de la acumulación de capital en la urbanización; o bien posibilita el consumo debido a la necesidad o a un derecho, sin contraprestación monetaria equivalente.

Como resultado, el suelo urbano y la vivienda, por ejemplo, pueden ser consumidos como bienes de uso, eliminando (o debilitando) su dimensión de bienes de cambio. Al mismo tiempo, ese acceso no mercantil, o no plenamente mercantil, inicial puede convertirse en una siguiente mercantilización. Ello es posible si ese suelo o vivienda es luego introducido en el mercado por parte del adquirente no mercantil o desmercantilizado 5 . Esta situación no es paradójica ya que, como vimos, el papel no mercantil de la intervención estatal se orienta a la superación de las contradicciones que para el desarrollo de los procesos de acumulación genera la tendencia a la universalización de la mercantilización (Offe 1990). Analizando esto brevemente, es posible percibir que ese papel estatal se destina a garantizar el desarrollo de las relaciones mercantiles que sustentan el proceso de acumulación capitalista.

La reestructuración neoliberal del capitalismo a nivel internacional, luego de la detención del proceso de crecimiento con pleno empleo, rentabilidad creciente y estabilidad que caracterizaron a los treinta años posteriores a la segunda posguerra, puede caracterizarse como la apropiación por el capital de una porción cada vez mayor del excedente, negando el acuerdo de bienestar: combinando el aumento de la productividad y el nivel de explotación; modificando el modelo de participación estatal, con énfasis en el dominio político y la acumulación del capital, en detrimento de la legitimación política y la redistribución social. La internacionalización de los procesos económicos (globalización) contribuyó a incrementar la rentabilidad y abrir mercados para su expansión (Castells, 1995: 52-57). Bastaría resaltar el creciente predominio del sector financiero y la financiarización de la economía en su conjunto, incluyendo la urbanización. Esos cambios económicos, sociales y políticos fueron justificados y valorados con el creciente predominio de ideas neoliberales (Harvey 2005).

\section{La urbanización en América Latina6}

Las contradicciones mencionadas se acentúan en las sociedades latinoamericanas, donde la urbanización se originó al incorporarse en la división internacional del trabajo como oferentes de bienes primarios para la industrialización en otros territorios. En ese contexto, la subordinación de los procesos locales de acumulación de capital, con la transferencia a las economías centrales de parte del excedente, frena el desarrollo de las fuerzas productivas y limita el dinamismo local. Una importante cantidad de población queda fuera del mercado de fuerza de trabajo, o se inserta en forma precaria y, al operar como ejército de reserva, contribuye a mantener bajos los salarios. En estas sociedades se exacerban las limitaciones del consumo mercantil, quedando 
fuera de las posibilidades de acceso monetario (solvencia) proporciones muy grandes de la población.

Por esas razones, la urbanización latinoamericana se caracteriza por la fuerte presencia de "prácticas sociales de consumo", en una gran heterogeneidad de situaciones. Desde la producción con predominio de la lógica de la necesidad, destinada al consumo directo en situaciones de "autoconstrucción" o de "autosuministro", y por ello de naturaleza "pre-mercantil" (Jaramillo, 2012: 72) o no mercantil, hasta la existencia de procesos de producción mercantil simple de bienes urbanos (Jaramillo, 2012; Abramo, 2012). Estos procesos, que se dan predominantemente fuera de relaciones mercantiles, están vinculados con actividades organizadas por esa lógica: la adquisición de materiales de construcción en el mercado es un ejemplo. El resultado es la "urbanización popular", que representa cerca de la mitad de la superficie y de la población en las grandes ciudades de América Latina (Duhau, 1998: 72-74).

Los estados latinoamericanos participan en la producción de la urbanización desde inicios del siglo XX, en intentos de responder a las necesidades de la acumulación económica y al fortalecimiento de la legitimidad política, garantizando a los trabajadores, y aún a la población no incluida en las relaciones salariales, cierto nivel en las condiciones materiales de subsistencia (Pradilla, 2009: 137-138). Si recordamos que en esas sociedades queda fuera de las condiciones mercantiles de reproducción cantidad importante de población, se configura un cuadro muy particular: las acciones estatales, si bien han tenido un desarrollo relevante en algunos países (Argentina, Brasil, México en particular), en algunos momentos (entre los años cuarenta y ochenta), no han logrado disminuir considerablemente el peso de la población trabajadora que está fuera de las condiciones mercantiles (Pírez 2000), ni han logrado institucionalizarse como "estado de bienestar" (Torre y Pastoriza, 2002).

Esas participaciones se caracterizaron por la debilidad estatal, propia de la acumulación capitalista subordinada y de la consecuente "limitación relativa de los recursos que la formación social como un todo puede destinar a la creación de estas condiciones generales de la acumulación, y en particular, a los valores de uso colectivo urbanos" (Jaramillo 1988: 28). Los recursos estatales se asignaron predominantemente para crear "valores de uso directamente ligados a la acumulación de capital, y en particular a la producción de mercancías, en detrimento de aquellos ligados con el consumo y, especialmente, con la reconstitución de las capas populares" (Íbid.). El Estado descargó sobre los sectores populares la provisión de algunos de esos bienes, en lo que se configuró como urbanización popular (Jaramillo 1988: 29 y 31). Esa descarga estatal fue acompañada, en gran medida, por relaciones de carácter clientelar.

La limitación de los procesos económicos y de la capacidad de inclusión de los mercados urbanos de fuerza de trabajo dio lugar a una mayor heterogeneidad de las fuentes de los recursos para la reproducción de la población. Así, junto con los originados en la renta, la ganancia y el salario, se encuentran procesos mercantiles simples que sostienen la reproducción de una cantidad relevante de familias, en múltiples actividades, muchas de ellas denominadas informales. Esto implica la existencia de un universo, también heterogéneo, muy amplio de sectores populares, es decir de familias que no logran su plena reproducción dentro de los procesos 
7 En México, por ejemplo, los créditos subsidiados otorgados por INFONAVIT en 2002 dejaban fuera al 61 por ciento de sus derechohabientes, cuyo ingreso no llegaba a un monto equivalente a seis salarios mínimos (Puebla 2006:197). mercantiles capitalistas, resultando en una de gran cantidad de población insolvente frente a buena parte de sus necesidades de reproducción y, en particular, respecto de los bienes urbanos.

Esa insolvencia se refiere, por un lado, a población sin capacidad monetaria para adquirir mercantilmente los bienes de la urbanización, pero con capacidad para ser sujeto de crédito subsidiado (desmercantilizado); y por el otro, población que, además de ser insolvente frente al mercado de los componentes de la urbanización, no logra las condiciones económicas para ser sujeto de crédito, aún desmercantilizado ${ }^{7}$. Se trata de una suerte de resto que indica una insolvencia particular. Las situaciones de insolvencia son dinámicas, ya que dependen de condiciones que se modifican en el tiempo, y sobre las que tienen influencia las políticas públicas: los ingresos sociales y la cobertura de los subsidios estatales, y la dinámica económica de los mercados de la urbanización.

Lo anterior permite entender que el acceso a la urbanización de gran cantidad de población no solvente ha quedado a cargo de los propios necesitados, con una limitada contribución (intervención) estatal. Los estados de la región descansaron (y descansan) explícita o implícitamente sobre el esfuerzo de los sectores populares para la provisión de algunos de esos bienes (Jaramillo 1988: 29 y 31).

Con el predominio de orientaciones neoliberales en América Latina, las reformas del Estado y de la economía impulsaron la reducción de aranceles, la liberalización financiera y cambiaria, la flexibilización laboral y, en particular, amplias privatizaciones. En la urbanización esos cambios promovieron ampliación de la mercantilización de la producción de vivienda (incluyendo casos de re-mercantilización), de las infraestructuras y de los servicios urbanos en general y, en particular, para la población de recursos limitados.

Con esa base, si se observa la urbanización latinoamericana, es posible identificar una particular heterogeneidad de formas para su producción y consumo, con una presencia significativa de formas no mercantiles y de desmercantilización social (no estatal).

\section{Heterogeneidad de la producción de la urbanización en América Latina}

Junto con los procesos mercantiles predominantes en la producción capitalista de la ciudad, tal como vimos, se encuentran de manera relevante otros mercantil simples y no mercantiles, así como junto con procesos de desmercantilización estatal y se observan otros de desmercantilización social.

La producción mercantil simplese destina al cambio igualitario y por lo tanto no significa la captación de recursos por encima del costo de los bienes que se intercambian (incluyendo aquí la reproducción de la fuerza de trabajo). La persistencia de estas formas productivas, aún dentro de la hegemonía de las relaciones mercantiles, es un rasgo constitutivo y peculiar (Jaramillo 2015) de las economías dependientes o periféricas como las de nuestra región. Los productos que surgen de esta forma productiva se integran al mercado y, por lo tanto, deben ser consumidos disponiendo recursos monetarios suficientes para ello. Esto es así, aunque los precios finales pudieran 
8 Gilbert menciona la importancia de la ayuda financiera dada por las redes sociales de las familias de bajos ingresos, frente a la no utilización del sistema bancario formal (Gilbert, 2012: IX).

9 Puede consultarse el clásico texto de Pradilla (1987:22). ser menores, aunque no siempre los sean, que los que se pagarían a un productor mercantil (Jaramillo 2015).

La producción no mercantil se orienta a la satisfacción de la necesidad de ciudad por medio de su consumo sin pasar por el mercado, sin buscar una ganancia. Esta modalidad se presenta en tres tipos de situaciones. Por un lado procesos estatales de producción de vivienda u otros bienes urbanos, como producción estatal directa; por otro lado, la producción por parte del propietario del suelo que encarga la construcción del bien (vivienda como acción individual o infraestructura como acción colectiva) a un productor mercantil o mercantil simple, y que lo destina para su consumo, sin introducirlo en el mercado (Jaramillo 1981:36; Pradilla 1987:23); por último, "las prácticas de hacer ciudad que efectúan los mismos pobladores empobrecidos..." (Jaramillo, 2012:33), en procesos que se orientan a la producción de la urbanización para su consumo en una lógica de necesidad (Pírez 1995). Esto último ha sido llamado en América Latina el hábitat popular, sustentado en procesos de autoconstrucción a través de diferentes modalidades: individuales (una familia) o colectivas (grupo de familias), organizadas formalmente (cooperativa o asociación) o no. En estos casos, el apoyo social suele incluir préstamos en dinero de parte de familiares o amigos ${ }^{8}$. La producción no mercantil suele incluir segmentos mercantilizados. En el primero y segundo casos puede tratarse de la construcción total o parcial por empresas capitalistas; mientras que en el tercero por la adquisición de materiales que no pueden ser autoproducidos ni "reciclados", así como la eventual utilización de mano de obra especializada (a veces producción mercantil simple), el alquiler comercial de maquinaria, etc. ${ }^{9}$. Sin embargo, el "motor de esa producción" (Jaramillo 1981:35), esto es la lógica que la organiza, es la satisfacción directa de la necesidad.

La significación social de la producción no mercantil de la urbanización depende de sus modalidades. La producción estatal directa, utiliza recursos obtenidos fiscalmente que se aplican en gastos de carácter redistributivo. La posibilidad de los aparatos estatales de operar como actores económicos sin obtener ganancia, dada su reproducción económica por medio de los impuestos, permite que la plusvalía producida y no apropiada por el estado sea transferida, tanto en favor del capital (al bajar el valor de la fuerza de trabajo) como en favor de la población (fuerza de trabajo o no) que puede acceder sin tener que disponer del dinero mercantilmente necesario. La producción no mercantil por encargo es llevada adelante por familias o individuos solventes que pueden adquirir mercantilmente el suelo, así como la construcción de la vivienda y el acceso a infraestructuras y servicios. Esa solvencia puede estar apoyada en la disponibilidad del crédito comercial o estatalmente subsidiado (desmercantilizado). Los recursos disponibles pueden aplicarse para contratar tanto a un productor mercantil como mercantil simple. En la producción no mercantil por autoproducción encontramos individuos, familias o grupos excluidos del circuito comercial y de las acciones estatales (no mercantiles o desmercantilizadas), sea porque éstas no existen, son limitadas o la población no reúne las condiciones requeridas para acceder a ellas.

Junto con situaciones de desmercantilización estatal, propias de condiciones de democratización del bienestar (Torre y Pastoriza 2002), encontramos procesos de desmercantilización social que incrementan la solvencia de los sectores populares a partir de acciones generadas por los mismos grupos sociales necesitados, sin 
10 De manera particular los casos de Chile y México, aunque ese "modelo" iniciado en el primer de ellas se ha expandido por toda la región. intervención estatal que implique algún tipo de redistribución económica. Esto indica que consumidores no solventes de ciudad asumen la carga de facilitar la solvencia de algunos de ellos aportando no únicamente su trabajo sino también recursos financieros obtenidos desde la limitación de otros consumos necesarios.

Tanto la producción no mercantil por autoproducción como la desmercantilización social, en la medida que implican esfuerzo en trabajo y recursos monetarios de parte de la población insolvente, sin transferencia estatal redistributiva, configuran situaciones que Lucio Kowarick (1979) Ilama de expoliación urbana.

En algunos casos se encuentran políticas o programas estatales que contribuyen con esos procesos no mercantiles o de desmercantilización social, incluyendo transferencia de recursos que significan cierta redistribución, sin que impliquen la subordinación del proceso.

Como parte de las trasformaciones ocurridas en las últimas décadas en una cantidad de países de la región ${ }^{10}$, encontramos intervenciones estatales destinadas a fortalecer los procesos de producción-consumo mercantiles disminuyendo, aún más, la producción-consumo no mercantil y desmercantilizada. Los bienes de la urbanización son configurados de manera creciente como bienes de cambio debilitando su condición de bienes de uso.

Es posible sintetizar esa nueva participación estatal en la re-mercantilización de procesos previamente desmercantilizados de manera total o parcial; y la mercantilización de bienes o procesos no mercantiles.

También se mercantilizan bienes y procesos originalmente no mercantiles. La introducción en el mercado de suelo excluido del mismo, tanto por tratarse de propiedad comunal como de propiedad pública (estatal). La transferencia al capital privado de infraestructuras o equipamientos (salud, educación y otros) producidos por el estado para el consumo directo. O bien de infraestructuras producidas no mercantilmente, por ejemplo, por cooperativas que prestan de la misma manera los servicios, que por estar localizadas en áreas de cobertura monopólica de las empresas privatizadas son sustituidas por éstas. Igualmente se transfiere a empresas privadas actividades de gestión (desde los diseños hasta las evaluaciones y controles) de la urbanización para sectores de recursos limitados, manteniendo a cargo de organismos estatales (no mercantiles) únicamente la oferta de recursos financieros.

Esa mercantilización de gran parte de los procesos de producción de la urbanización incluye el peso creciente del capital financiero, cuya lógica de valorización tiende a subordinarlos. Esa participación está asociada también a cambios en la regulación que la permiten y vehiculizan, así como a la presencia de operadores internacionales.

Todas esas medidas estatales podrían quedar cubiertas (escondidas) detrás del crecimiento de los procesos mercantiles. Sin embargo, no se deben a la mera dinámica del mercado, sino que, por el contrario, son el resultado de los cambios institucionales que resultan de decisiones estatales (políticas). Por consiguiente, es 
11 Gilbert (2012) habla de mercado secundario.

12 Entre 1976 y 2003 ese promedio anual fue de 1476,1 viviendas terminadas. relevante identificar esas situaciones y colocarlas dentro del conjunto heterogéneo de modalidades de producción-consumo de la urbanización en América Latina.

La mencionada multiplicidad de los procesos de producción de la urbanización suele darse de manera combinada, integrando lógicas diferentes con el predominio de alguna de ellas. Esa combinación de lógicas puede percibirse tanto de manera sucesiva, en los diferentes momentos de la urbanización, como simultánea en cada uno de ellos. Es un lugar común afirmar que la urbanización latinoamericana muestra una enorme proporción de la superficie de las ciudades urbanizada predominantemente por fuera del mercado y del Estado. Esto significa que, junto con las áreas urbanizadas por una combinación de lógicas mercantiles y estatales, se encuentran otras producidas fuera de ellas. Al mismo tiempo, en estas sociedades caracterizadas, también, por la tendencia a la mercantilización universal y hegemónica, es difícil la ausencia total de relaciones mercantiles, aunque puede reconocerse la exclusión de su predominio. Es también difícil que se produzcan acciones totalmente fuera de las regulaciones y apoyos estatales, pero es más importante la ausencia del Estado como urbanizador. Por otra parte, la producción popular, no mercantil, que es consumida sin pasar por el mercado, puede incluir la intervención actores que desarrollan otras lógicas (mercantil, mercantil simple). Asimismo, esa producción no mercantil puede ser introducida en el mercado y dar lugar a procesos mercantiles de consumo. Es evidente que la urbanización popular, más allá de que se produzca como bien de uso, al ser un producto del trabajo humano y contener un tiempo determinado de éste, tiene valor y es posible asignarle un precio en el mercado que puede realizarse si su productor deja de consumirla y la introduce en el cambio (Pradilla 1987:19). Esa incorporación, como venta o alquiler, generalmente en términos de lo que se ha Ilamado el mercado urbano informal ${ }^{11}$ (Abramo 2012, Cravino 2006), produce un cambio importante: el acceso a esos bienes depende de la disponibilidad de dinero (no necesariamente en cantidades análogas al mercado inmobiliario formal) (Cravino 2006) y se introduce en relaciones de acumulación económica. Las modificaciones que se están produciendo en buena parte de las áreas urbanas informales de América Latina están relacionadas con ese desarrollo de la mercantilización de las viviendas allí existentes.

Las formas no plenamente mercantiles de producción de la urbanización en las principales ciudades de América Latina son fenómenos persistentes que representan una proporción muy relevante de la superficie urbanizada y de la población asentada. Es difícil su cuantificación, ya que pocas veces existe información que la recoja. Su importancia relativa puede percibirse al observar la relación que se da entre urbanización formal para sectores de bajos recursos y la producción popular de vivienda. Por ejemplo, en los primeros años de la década del 2000 en el Área Metropolitana de Buenos Aires (AMBA), la producción estatal de vivienda social, que fue muy superior a la de las décadas anteriores, representó un promedio anual de 11640,7 viviendas terminadas ${ }^{12}$, mientras entre 2001 y 2006 el promedio anual de familias que se asentaron de manera informal fue de 18165 (Varela y Wagner, 2012 y Betatis et al, 2012).

El Cuadro 1 esquematiza la gran complejidad de la producción y el consumo de la urbanización en las sociedades latinoamericanas. 
Cuadro 1 - América Latina: Diferentes modalidades de producción-consumo de la urbanización. Fuente: Elaboración del autor.

\begin{tabular}{|c|c|c|c|c|}
\hline \multirow[t]{3}{*}{ Producción } & \multicolumn{4}{|l|}{ Consumo } \\
\hline & \multirow[t]{2}{*}{ Mercantil } & \multirow{2}{*}{$\begin{array}{l}\text { No } \\
\text { Mercantil }\end{array}$} & \multicolumn{2}{|c|}{ Desmercantilizado } \\
\hline & & & Estatal & Social \\
\hline Mercantil & 1 & 2 & 3 & 4 \\
\hline Mercantil Simple & 5 & 6 & 7 & 8 \\
\hline \multicolumn{5}{|l|}{ No mercantil } \\
\hline Estatal & 9 & 10 & 11 & 12 \\
\hline Por encargo & 13 & 14 & 15 & 16 \\
\hline $\begin{array}{l}\text { Autoproducción } \\
\text { ("urbanización popular") }\end{array}$ & 17 & 18 & 19 & 20 \\
\hline Desmercantilizada estatal & 21 & 22 & 23 & 24 \\
\hline Desmercantilizada social & 25 & 26 & 27 & 28 \\
\hline
\end{tabular}

Veamos tales situaciones:

\section{Producción mercantil}

El caso modélico es la situación 1: se produce aquello que tiene demanda solvente dado que se orienta a satisfacer una necesidad (bien de uso) en la medida que, siendo introducido en el mercado, recibe a cambio una cantidad de dinero que, además de recuperar los costos, permite realizar la ganancia (bien de cambio). Es el proceso predominante en el capitalismo.

El consumo de los bienes producidos mercantilmente puede darse sin que los consumidores dispongan de la totalidad de los recursos monetarios necesarios, en situaciones de desmercantilización del consumo que aparecen indicadas como 3 y 4 en el Cuadro 1. La situación 3, cuando los bienes de la urbanización producidos mercantilmente son accedidos por la eliminación o disminución de la necesidad de los consumidores de disponer de dinero debido a alguna forma de intervención estatal (subsidio) que tiende a redistribuir recursos para lograr esa accesibilidad, incrementando de ese modo la solvencia. Son casos de acceso a suelo, a vivienda o al consumo de servicios como los de agua y drenaje, electricidad o gas. Esa desmercantilización del consumo permite mantener la producción capitalista, facilitando el acceso a la urbanización con relativa independencia de las condiciones económicas de los individuos o familias. Para ello, entre el productor capitalista y el consumidor interviene algún mecanismo ajeno al mercado que hace posible la remuneración del capital, y la obtención de ganancia, y, a la vez, el acceso al bien por parte de individuos o familias sin aportar recursos monetarios propios. El Estado asume, total o parcialmente, las cargas monetarias que garantizan el consumo, normalmente como resultado del reconocimiento de un derecho. El origen de los recursos que se utilizan en esa desmercantilización 
13 Es evidente la necesidad de diferenciar la perspectiva jurídica que tiende a reconocer únicamente la definición formal-legal de esas situaciones. (ganancias o salarios, por ejemplo), permitirá o no procesos de redistribución en los procedimientos de desmercantilización.

Junto con la existencia de procesos estatales de desmercantilización, y en gran medida debido a su debilidad y/o limitación, encontramos casos que llamamos de desmercantilización social (4). Se trata de procesos de urbanización producidos mercantilmente que son accedidos porque se elimina o disminuye la necesidad de dinero, pero no por una intervención estatal en favor de población insolvente, sino por medio de procesos solidarios organizados de manera autónoma por individuos, familias o grupos de sectores populares. Puede tratarse de aportes económicos cooperativos, etc. Al no existir transferencias financieras estatales no hay redistribución

Más allá de lo anterior, la producción mercantil puede ser objeto de procesos de consumo diferentes. La situación 2 hace referencia a un consumo no mercantil de un bien mercantilmente producido, como puede ser suelo, vivienda, infraestructuras o servicios. Esto puede ocurrir en dos situaciones principales: cuando el Estado se hace cargo del bien producido y lo transfiere en forma gratuita por fuera del mercado; o cuando suelo o vivienda producidos mercantilmente son objeto de una ocupación de hecho (invasión) o infraestructuras y/o servicios urbanos mercantilizados son objeto de un uso clandestino. Esos consumos, sea de población necesitada e insolvente o de población solvente, suponen una posible contradicción con el derecho de propiedad, que los lleva a ser caracterizados como ilegales y, en algunos casos, como delitos ${ }^{13}$. Utilizamos el potencial porque dentro de ciertas condiciones la ocupación de una propiedad inmueble, por ejemplo, puede dar lugar a la creación de un derecho, cuando se constituye en un antecedente para adquirir institucionalmente el bien por el paso de tiempo, en situaciones de "usucapión".

\section{Producción mercantil simple}

Una situación particular de producción mercantil, la mercantil simple, tiende a concretarse, como mencionamos, por medio de consumos mercantiles (5): para acceder al bien se debe aportar la cantidad de recursos monetarios que responde al cálculo económico del productor, de manera análoga a lo que sucede con la producción plenamente mercantil (1). Igualmente podría ser consumida con base en alguna desmercantilización estatal (7), por ejemplo, con un crédito subsidiado, o por medio de una desmercantilización social (8). Un consumo no mercantil, por ejemplo, la ocupación de una vivienda construida por un productor mercantil simple (6), sería análogo a la misma situación de una producción plenamente mercantil (2).

\section{Producción no mercantil}

La modalidad no mercantil muestra una heterogeneidad mayor, tanto en la producción como en el consumo. Es posible encontrar tres casos de producción no mercantil: estatal, por encargo y por autoproducción. Esta última, por su parte, podrá ser individual o colectiva, y por fin, organizada o no.

La producción no mercantil supone un consumo correlativo que no pasa por el mercado, por lo que no requiere aportar recursos monetarios $(10,14$ y 18$)$. 
Pero existen otras situaciones. Por una parte, producción no mercantil y consumo mercantil. La concreción más común aquí es la posterior introducción del bien urbano en el mercado: el adquirente no mercantil de vivienda estatal, el propietario que produjo por encargo su vivienda para habitarla y el autoconstructor popular pueden introducir esa vivienda en el mercado. Se trata de submercados diferentes según las condiciones. La situación más simple es la de un propietario legal del suelo que encarga la construcción de la vivienda para habitarla y luego la introduce, en venta o alquiler, al mercado (13) formal, para lo cual no encontrará ningún obstáculo más allá de las condiciones de ese mercado. En el caso de la producción no mercantil estatal (9) si no existen restricciones para su posterior disposición mercantilizada, esa mercantilización del consumo sería análoga a la anterior, es decir por la mera introducción en el mercado inmobiliario. Si existen restricciones, estas podrían obligar a una mercantilización informal. Análogo será el caso de un proceso de autoproducción no mercantil (17) en donde con el tiempo la vivienda es introducida en el mercado informal, en venta o alquiler. Todas estas situaciones suponen la existencia de bienes producidos para el consumo directo que son introducidos en relaciones mercantiles y que, en consecuencia, requieren del aporte monetario para su consumo. En esos casos será relevante identificar la significación de ese aporte monetario y, consecuentemente, del peso real de tal mercantilización. Un caso particular se configura cuando se retira del mercado un bien por su ocupación (2) y, en un segundo momento, a partir de esta nueva situación no mercantil, es mercantilizado por ese primerocupante para permitir otros usos por medio del pago de una cantidad determinada de dinero.

Dentro de la producción no mercantil estatal debemos incluir los casos de reconocimiento de propiedad del suelo excluida del mercado, como son las formas comunales. Cuando sobre ese tipo de suelo se produce un proceso de urbanización, su producto quedará fuera del mercado. Puede darse en condiciones tradicionales de propiedad comunal, cuyo uso es parte del carácter de miembro del grupo. Ese derecho colectivo no puede ser enajenado por los individuos que integran el grupo ni por el grupo como tal, sino que se transmite entre los miembros como condición de la reproducción colectiva y de sus miembros individuales. Incluimos estas situaciones en la producción no mercantil estatal ya que dependen del reconocimiento legal de esa forma de propiedad de suelo. Un caso particular es la de las tierras ejidales, como consecuencia de la reforma agraria posterior a la Revolución Mexicana y anterior a la reforma de los años noventa del siglo pasado: tierras comunes cuyo usufructo corresponde a un grupo social determinado (campesino) y que no pueden ser introducidas en el mercado (Salazar 2012).

La producción no mercantil mercantilizada podría ser consumida con base en algún mecanismo estatal que permitiera adquirir solvencia para la misma (11, 15 y 19). En estos casos se trataría de procesos legales de mercantilización de la producción originalmente no mercantil, o bien implicarían el reconocimiento estatal de esa mercantilización y la consecuente desmercantilización de su consumo. Pero en los otros casos $(12,16$ y 20), cuando la desmercantilización se basa en aportes sociales, es posible el acceso al consumo mercantilizado con el apoyo solidario para incrementar la capacidad monetaria (solvencia) por fuera de los procesos estatales, tal como hemos visto.

Un caso particular, que podría considerarse una forma de producción no mercantil de vivienda es el que diseña la legislación uruguaya sobre vivienda y cooperativas. El resultado es un sistema cooperativo de vivienda de usuarios, en el cual la cooperativa 
es propietaria de las viviendas, y el socio es adjudicatario de las mismas (con el "uso y goce") (Franco y Raffo 2014: 65).

\section{Producción desmercantilizada}

La urbanización puede ser producida con base en el apoyo estatal desmercantilizador (en el financiamiento, el costo de los materiales, con exenciones impositivas, etc.) para ser introducido de manera plena al mercado (21). Esa transferencia estatal podría tener dos efectos diferentes. Por un lado, el productor podría beneficiarse totalmente con ese apoyo, vendiendo en el mercado los bienes al precio normal, captando de esa manera una sobre ganancia. Por otro lado, la disminución de los costos de producción por la desmercantilización estatal, podría reflejarse en un precio menor que en la producción meramente mercantil, consumiéndose esos bienes con un esfuerzo monetario correlativamente menor, que no afectaría la ganancia del productor mercantil, garantizada por la transferencia desmercantilizadora.

El consumo de ese bien podría ser también el resultado de un proceso estatal de desmercantilización (23), disminuyendo, por ejemplo, los costos financieros de la operación, o bien de alguna desmercantilización social (24).

En estos casos se podría encontrar otra situación basada en diferentes tiempos. Tal sería una vivienda que fue adquirida con base en su producción desmercantilizada y posteriormente es introducida en el mercado.

Si la desmercantilización de la producción es social, el productor obtiene de apoyos solidarios (familiares o comunitarios) recursos financieros o mejores costos en los materiales para sostener la producción de la vivienda, que luego es introducida en el mercado (25). En este caso se dan las mismas situaciones: si el bien es introducido a precios del mercado formal, el productor recuperaría una cantidad mayor de la que puso, a costa de quienes contribuyeron a la disminución de sus costos; si el bien es introducido con precios menores gracias a la desmercantilización social, serían de adquisición menos pesada en términos monetarios. Ese consumo, por su parte, podría estar apoyado en algún proceso estatal de desmercantilización (27), siendo el más común, el crédito subsidiado, o bien el comprador podría basarse en el apoyo familiar o comunitario (28).

Es también lógicamente posible el consumo no mercantil de la urbanización producida en casos de desmercantilización estatal (22) o social (26).

\section{Conclusiones}

Se ha intentado poner en evidencia la enorme heterogeneidad de las formas de producción y consumo de los componentes de la urbanización en las sociedades

14 Según el diccionario de la RAE, trayectoria es el "curso que, a lo largo del tiempo, sigue el comportamiento o el ser de una persona, de un grupo social o de una institución." (Segunda acepción). latinoamericanas $y$, además, las complejas relaciones que existen entre ellas, así como su dinámica. Como se vio, lo que puede comenzar mercantilmente puede continuar no mercantilmente y volver a una modalidad mercantil, y así con muchas combinaciones. Puede preguntarse de qué depende tal dinámica y las combinaciones que la constituyen. Esto conduce a pensar en la configuración de trayectorias ${ }^{14}$ en los 
procesos de producción de la urbanización. En principio, y conociendo la cantidad de diferentes experiencias en la región, es posible entender que esos sinuosos cursos en la producción de la urbanización están relacionados con elementos estructurales como con situaciones coyunturales de esas sociedades.

La revisión, rápida, de esa heterogeneidad y su dinámica, permite percibir el predominio de las formas mercantiles. Predominio tanto actual como, fundamentalmente, tendencial. Podría pensarse que la urbanización es por lo tanto el resultado de las contraposiciones entre esas diferentes formas de producción-consumo y que, detrás de ellas, se encuentran distintas significaciones de la ciudad: desde la ciudad como plena obtención de ganancia, hasta la ciudad como satisfacción de la necesidad de residir para garantizar la reproducción familiar. Esas múltiples contraposiciones (contradicciones) muestran, desde este ángulo, a la ciudad como resultado de controversias (luchas) sociales. En este contexto, parece evidente que la creciente mercantilización, que tiende a garantizar la reproducción del capital en la producción de la urbanización, pone simultáneamente en cuestión la reproducción de la población (no únicamente de la fuerza de trabajo). Esto significa que las contradicciones a que da lugar, como observa Offe (1990), muestran que el predominio mercantil impide garantizar la reproducción de la totalidad social. De allí, buena parte de las formas diferentes, sus relaciones y contradicciones, tal como se ha expuesto en el artículo. De allí también, la consagración (por medio de la ley) de algunas de ellas como regulares, merecedoras de la defensa estatal; y otras como clandestinas (informales), merecedoras muchas veces de la coerción.

Los componentes estructurales, que definen los procesos de mercantilización creciente, introducen límites precisos para la conformación de los procesos reales de producciónconsumo de los componentes urbanos. Pero al mismo tiempo, esas condiciones estructurales son la base de la configuración de contra movimientos que intentan superar las contradicciones que ellas mismas generan: así las diferentes modalidades de participación estatal, por una parte, como también los comportamientos sociales desde fuera de la producción predominante que buscan garantizar la reproducción de ciertas familias, más allá de sus capacidades monetarias y, por lo tanto, más allá de los procesos cerrados y contradictorios de producción-consumo mercantil.

Es posible, también, pensar que el conocimiento de esas trayectorias y de sus intersecciones permite entender de manera más precisa el sesgo de la dualidad que suele introducirse cuando se analiza la realidad urbana de la región en términos de procesos y fenómenos formales e informales.

Las proposiciones anteriores vinculan la configuración de las trayectorias de la urbanización con sus condiciones estructurales y con el comportamiento de diferentes actores: económicos, fundamentalmente financieros hoy; sociales populares y estatales.

Al pensar el papel del Estado en la urbanización latinoamericana resulta difícil atribuirle una función estructural, salvo en un análisis de gran abstracción y generalidad, como podría ser garantizar las condiciones urbanas para la reproducción de la formación social. Sin embargo, con ese registro no parece posible identificar la significación histórica de las políticas estatales. Es también una proposición de alta abstracción, aunque apunta a procesos más concretos, la postulación de que el Estado se hace 
cargo de las cuestiones que no pueden ser resueltas por los capitales particulares. Parece más bien que en diferentes tiempos el Estado tendería a garantizar dos objetivos no necesariamente confluyentes: la reproducción global y la acumulación particular, generando condiciones para que fuesen mínimas las contradicciones entre ambos, de manera de ampliar la cobertura de los procesos de acumulación de los capitales particulares. Esta perspectiva obliga a preguntar sobre las condiciones históricas de las lógicas identificadas en la producción de la ciudad: mercantil, estatal y social (necesidad), y sobre la tendencia a asociar el papel estatal con una orientación denominada pública (de integración, de bien de uso, etc.) (Pírez 1995). Es preciso poner en cuestión esas generalizaciones, a partir del conocimiento de los procesos concretos de urbanización. Particularmente, dada la heterogeneidad presente en el capitalismo dependiente.

Lo anterior cuestiona también la simplificación del papel estatal al asociarlo con una determinación estructural. Por el contrario, apunta a la necesidad de conocer los procesos políticos que, en diferentes momentos, van dando realidad concreta a las intervenciones estatales que, sin duda, parten de una coerción estructural. Coerción que no necesariamente opera en el sentido de una fuerza por fuera de las relaciones sociales, sino que se concreta, también, en actores y relaciones, configurando situaciones políticas (correlaciones de fuerza, etc.). La atención de los procesos de la urbanización según diferentes tiempos (ciudad liberal, de bienestar, neoliberal) hace referencia a distintas configuraciones políticas que resultan de los procesos económicos y sociales que tienden a orientar las relaciones de producción de la ciudad en relación con cada uno de esos tres objetivos: subordinación al desenvolvimiento libre del capital, integración con base en la distribución y el incremento de la productividad, y reconstitución del poder de clase en sus dimensiones económicas (acumulación) y políticas.

Cuando se menciona configuraciones políticas se piensa necesariamente en actores y sus relaciones en términos, predominantemente, de capacidad (poder) para ordenar los componentes de la producción de la urbanización en razón de sus intereses y/o necesidades. Si bien no es este el momento para desarrollar estas ideas, es evidente que el predominio, por ejemplo, de los procesos de ampliación de la mercantilización o re-mercantilización que caracteriza a las orientaciones neoliberales significa un reconocimiento de modificaciones en las relaciones de fuerza como fortalecimiento de las fuerzas económicas y políticas que se mueven por la acumulación (más bien por el despojo). Un ejemplo es la consolidación de la producción de vivienda social en una situación caracterizada por tres dimensiones: extrema mercantilización de la vivienda (aun con su degradación como bien de uso), desmercantilización de su consumo (facilitación estatal de su realización como mercancía) y predominio de la lógica financiera en todo el proceso (financiarización) (Pírez 2014).

Al mismo tiempo, los cruces no mercantiles en trayectorias mercantiles, o el origen no mercantil de otras trayectorias, muestran, en esa heterogeneidad de la producción urbana en América Latina, la existencia de áreas en las que las correlaciones de fuerza son diferentes de aquellas que aparecen como globalmente predominantes en cada una de esas sociedades.

Las diferentes modalidades y, particularmente, la presencia de las no mercantiles, tanto de manera autónoma como subordinada, introducen un elemento interesante, no solamente para comprender la urbanización, sino también para pensar en su 
15 Basta revisar la literatura sobre "hábitat popular" o "producción social del hábitat". transformación. De manera inmediata aparece una cuestión sobre la posibilidad de procesos no capitalistas de urbanización en sociedades de capitalismo dependiente. Más allá de la evidente contradicción que implica esa proposición, debería explorarse la producción (y consumo, obviamente) no mercantil a partir de la gran cantidad de experiencias que se aproximan a esa condición, en complejas y contradictorias relaciones con las formas predominantes. Algunas alternativas pueden ser interesantes como intentos para superar la subordinación popular a la acumulación de capital en el acceso a sus condiciones de asentamiento urbano. Son muchas las experiencias, a las que se hizo referencia, de producción no mercantil de componentes de la urbanización ${ }^{15}$. Agreguemos dos comentarios: la literatura suele afirmar que las infraestructuras y servicios más avanzados tecnológicamente no son susceptibles de ser autoproducidos. Sin embargo, las mismas tecnologías parecen abrir nuevas posibilidades, como ocurre con la telefonía celular autogestionada por la comunidad indígena de Talea de Castro en el estado de Oaxaca en México (Pérez Salazar, 2013). Puede pensarse, también, en la posibilidad de liberar, relativamente al menos, a la población de las condiciones estructurales de la determinación de solvencia/insolvencia, implementando sistemas de ingreso ciudadano o renta básica que garantizan un ingreso por fuera de la mercantilización de la fuerza de trabajo; asimismo con la organización de bancos comunitarios que presten servicios financieros solidarios.

Para avanzar en el sentido de esas trasformaciones, tal vez sea conveniente trabajar sobre el derecho a la ciudad y la superación de las restricciones estructurales (su contradicción con la mercantilización y con la propiedad privada individual excluyente), y al mismo tiempo con su capacidad para configurar fuerzas transformadoras de las modalidades predominantes de la producción-consumo de la urbanización. Esto, sin dudas, llevaría a significar su definición desde las relaciones políticas y las luchas sociales y, en definitiva, en su nexo con el papel del Estado.

\section{Referencias bibliográficas}

ABRAMO, P. (2012), "La ciudad informal com-fusa: El mercado y la producción de la territorialidad urbana popular" en Salazar, Clara (coord.): Irregular. Suelo y mercado en América Latina. México: El Colegio de México. pp. 85-124.

BETATIS, Clarisa et al. (2012) "De villa a 'Barrio'" en Cravino, María Cristina (org.) Construyendo barrios. Transformaciones socioterritoriales a partir de los Programas Federales de Vivienda en el Área Metropolitana de Buenos Aires (2004-2006), Buenos Aires, Ediciones Ciccus-Universidad Nacional de General Sarmiento, pp. 171-205.

CASTELLS, M. (1995), La ciudad informacional. Tecnologías de la información, reestructuración económica y el proceso urbano. Madrid: Alianza Editorial.

CRAVINO, Cristina: Las villas de la ciudad. Mercado e informalidad urbana, Los Polvorines: Universidad Nacional de General Sarmiento, 2006.

DUHAU, E. (1998). Hábitat popular y política urbana. México: Miguel Ángel Porrúa-UAM.

ESPING-ANDERSEN, G. (1993), Los tres mundos del Estado del Bienestar, Valencia: Edicions Alfons El Magnànim-Generalitat Valenciana-Diputació Provincial de València.

FRANCO, Jorge y RAFFO, Alberto (2014): "La utopía realizable de la 'propiedad colectiva'" en Aravena, Susana et al. La vivienda, entre el derecho y la mercancía. Las formas de propiedad en América Latina, Montevideo: Trilce-WE EFFECT, pp. 63-76. 
GILBERT, Alan (2012) "De Soto's The Mystery of Capital: reflections on the book's public impact", en International Development Planning Review, 34 (3) January 2012, pp. vi-xvii.

HARVEY, David (2005), A brief history of neoliberalism, Oxford-New York: Oxford University Press

JARAMILLO, Samuel (1981) Producción de vivienda y capitalismo dependiente: el caso de Bogotá, Bogotá: CEDE-Uniandes.

Jaramillo, Samuel (1988), "Crisis de los medios de consumo colectivo urbano y capitalismo periférico" en Cuervo, L.M., Jaramillo S., González, J.I. y Rojas, F., Economía política de los servicios públicos. Una visión alternativa. Bogotá: CINEP, pp. 15-37.

(2012), “Urbanización informal: diagnósticos y políticas: Una revisión al debate latinoamericano para pensar líneas de acción actuales" en Salazar, Clara (coord.): Irregular. Suelo y mercado en América Latina, México: El Colegio de México. pp 33-84.

(2015) "Heterogeneidad estructural en el capitalismo. Una mirada desde la teoría del valor trabajo abstracto" en II Seminario Internacional: La fase actual del capitalismo y la urbanización en América Latina, 18-20 febrero 2015, Medellín.

KOWARICK, Lucio (1979): A espoliação urbana, Paz e Terra, Rio de Janeiro.

MARX, Carlos (1973) El Capital. Critica de la Economía Política, T.I, México: Fondo de Cultura Económica.

OFFE, C. (1990), Las contradicciones del Estado del Bienestar, Madrid: Alianza.

PÉREZ SALAZAR, Juan Carlos (2013) "El pueblo indígena que creó su propia red de telefonía móvil" en BBC Mundo Noticias, 15/10/2013.

PÍREZ, Pedro (2000) Servicios urbanos y Equidad en América Latina. Un panorama con base en algunos casos. Serie Medio Ambiente y Desarrollo, 26. Santiago de Chile: CEPAL. 2000, 86 p.

(2014), "La mercantilización de la urbanización. A propósito de los 'conjuntos urbanos' en México", Estudios Demográficos y Urbanos, vol. 29, núm. 3 (87), pp. 481-512.

(2016) "Buenos Aires: La orientación neoliberal de la urbanización metropolitana" en Sociologías 42, pp.90-118.

PRADILLA, Emilio (1987) Capital, Estado y vivienda en América Latina, México: Fontamar.

(2009), "Acumulación de capital y estructura territorial en América Latina: teoría e historia" en Pradilla, E. (comp.), Los territorios del neoliberalismo en América Latina. México: UAM-Porrúa. pp. 15-90.

(2013) "La economía y las formas urbanas en América Latina" en Ramírez, Blanca Rebeca y Emilio Pradilla Cobos (Comp.), Teorías sobre la ciudad en América Latina, Vol 1., México: UAM.

PUEBLA, Claudia (2006) "El Instituto del Fondo Nacional de la Vivienda para los Trabajadores (Infonavit)" en Coulomb, René y Martha Schteingart (coords.), Entre el Estado y el mercado. La vivienda en el México de hoy, México: UAM-A-Miguel Ángel Porrúa, pp. 193-238.

SALAZAR, Clara (2012), "Los ejidatarios en el control de la regulación" en Salazar, Clara (Coord.), Irregular. Suelo y mercado en América Latina, México, México: El Colegio de México, pp. 265-305.

TOPALOV, Christian (1979), La urbanización capitalista, México: Edicol.

TORRE, Juan Carlos y Elisa Pastoriza (2002) "La democratización del bienestar", en Torre, Juan Carlos (Director), Los años peronistas (1943-1955), Buenos Aires: Sudamericana, p 257-312.

VARELA, Omar y Raúl Fernández W (2012) "El retorno del Estado" en Cravino, María Cristina (org.) Construyendo barrios. Transformaciones socioterritoriales a partir de los Programas Federales de Vivienda en el Área Metropolitana de Buenos Aires (2004-2006), Buenos Aires: Ediciones Ciccus-Universidad Nacional de General Sarmiento, pp 15-48. 